\title{
Unindo o Útil ao Agradável: Ação de Extensão de Formação em Informática para Mulheres em Vulnerabilidade Social
}

\author{
Renata Luiza da Costa ${ }^{1}$, Celyce de Sousa Gonçalves Lula ${ }^{1}$, Débora Guerra de S. \\ Guinati $^{2}$, Stéfany de Castro Souza ${ }^{2}$ \\ ${ }^{1}$ Departamento Acadêmico - Instituto Federal de Goiás (IFG) \\ Av. Universitária s/n Vale das Goiabeiras - Inhumas - Goiás - Brasil \\ ${ }^{2}$ Estudante do Bacharel. em Sistemas de Informação - Instituto Federal de Goiás (IFG) \\ Av. Universitária s/n Vale das Goiabeiras - Inhumas - Goiás - Brasil \\ \{renata.costa, celyce.lula\}@ifg.edu.br, guinati7@gmail.com, \\ stefanydecastrosousa@hotmail.com
}

\begin{abstract}
This paper presents the results of a computer training course developed for women in social vulnerability. Based on the interest in offering opportunities for professional learning and the reality of the deficit of women professionals in the field of Computer Sciense, the proposal integrated contents from Basic Informatics, Entrepreneurship, Gender and Motivational Discussions, and Website Design. Among other results, it was possible to perceive that extension is a way to attract women to the referred area, but for them to remain in the courses, it was also identified that other assistance support measures are necessary, in view of the social vulnerability profile.

Resumo. Este artigo apresenta resultados de uma ação de formação em informática desenvolvida para mulheres em vulnerabilidade social. A partir do interesse em oferecer oportunidade de aprendizagem profissional e da realidade de déficit de profissionais mulheres na área da Informática, a proposta integrou conteúdos de Informática Básica, Empreendedorismo, Discussões de Gênero e Motivacionais, e Design de Sites. Dentre outros resultados, foi possível perceber que a extensão é um caminho para atração de mulheres para a área da Informática, mas, para que permaneçam nos cursos, também foi identificado que são necessárias outras medidas de apoio assistencial, tendo em vista o perfil de vulnerabilidade social.
\end{abstract}

\section{Introdução}

Um problema social muito comum em países subdesenvolvidos e em desenvolvimento é a quantidade de mulheres em situação de vulnerabilidade social. Mulheres em tal situação e, também, devido a outras razões culturais, comumente, se submetem a situações de violência física, psicológica e simbólica em suas diversas formas.

As diferenças de cor, sexo e ocupação geográfica levam a piores índices de vulnerabilidade social, em alguns casos. Por exemplo, as taxas de mulheres, mães de família e adolescentes entre 10 e 17 anos grávidas, ainda é de, aproximadamente, 7\% no Brasil [Rocha et al 2017]. Além disso, os resultados da pesquisa do Atlas da Violência no Brasil, conduzida pelo Instituto de Pesquisa Econômica Aplicada (IPEA) mostram 
que, em dez anos (2006-2016), a taxa de feminicídio aumentou 6,4\% [IPEA 2018].

Para o enfrentamento e superação da situação vulnerável pelas mulheres, é imprescindível ir além da oferta de programas de assistência social e apoio à mulher, necessitando propor alternativas de outro modo de vida para elas [IPEA 2018]. Isto quer dizer que é imprescindível incluir, dentre outras coisas, formação e profissionalização para elas de modo que possam repensar e planejar um recomeço profissional e de vida.

Outro problema social que vem sendo evidenciado por várias instituições de pesquisa e de tecnologia nos últimos anos é o déficit de mão de obra qualificada em Informática, em suas diversas subáreas. Trata-se de um problema de ordem mundial, na verdade, pois a velocidade com que se forma pessoas é bem aquém em relação à velocidade com que a tecnologia avança e torna a sociedade cada vez mais dependente, especialmente, de tecnologias digitais, o que quer dizer, também, que cada vez mais, aumentam-se postos de trabalho nessa área [ISACA 2016; Softex 2013a, 2013b]. Algumas dessas pesquisas ainda mostram o baixo índice de mulheres atuantes nas profissões ligadas à Informática [Aires et al 2018; ISACA 2016; IAB 2015].

Concernente à baixa formação de profissionais na área da informática, é relevante destacar que, no caso do Brasil, sequer o letramento digital foi universalizado. Pesquisas do Instituto Brasileiro de Geografia e Estatística (IBGE) revelam que 33\% da população brasileira ainda é, de alguma maneira, excluída digitalmente [IBGE 2018]. Pesquisa do Comitê Gestor da Internet no Brasil (CGI.br) mostra, também, essa outra repercussão de desigualdade social: $50 \%$ da população brasileira das classes $\mathrm{D}$ e E não tem acesso à Internet [CGI.br 2019], sem falar no não conhecimento a respeito dos usos de Tecnologias Digitais da Informação e Comunicação (TDIC).

Considerando as realidades supramencionadas, foi projetada a ação de extensão intitulada Mulheres na Informática: Da informática básica à criação de sites, com vagas exclusivas para mulheres em comprovada situação de vulnerabilidade social. Assim, este artigo tem por objetivo apresentar levantamento bibliográfico sobre a representação feminina nas profissões das Ciências Exatas, relatar o desenvolvimento da supracitada ação de extensão, de seus preceitos teórico-metodológicos e seus resultados.

\section{A Representação das Mulheres nas Profissões das Ciências Exatas e as Bases dos Estigmas Femininos}

A importância das TDIC para o mundo é atual e não futura. Quanto mais a sociedade tem tais tecnologias desenvolvidas e mais pessoas e ramos profissionais fazem uso delas, mais demanda há por profissionais qualificados que consigam sustentar e realimentar essa estrutura. Exemplos disso, no Brasil, são a Base Nacional Comum Curricular (BNCC) que indica conhecimentos de TDIC como competências imprescindíveis desde a Educação Básica e a quantidade de serviços governamentais que vem sendo oferecidos somente em modo digital [Costa 2020]. Apesar desse cenário, há um grande déficit de profissionais de Tecnologias da Informação e Comunicação (TIC) pelo mundo [Softex 2013a, 2013b; ISACA 2016].

Pensando nisso, diversas instituições têm estimulado programas específicos para incentivar mulheres a escolherem profissões na área de TIC. Os problemas de desigualdade de gênero na área das Exatas são de longa data. Historicamente, mulheres são estigmatizadas como quem tem inteligência menor para atuação profissional nas Ciências Exatas [Chassot 2011b; Costa et al 2019]. 
Pesquisas do IBGE [IBGE 2017] mostram que o número de mulheres no mercado de trabalho vem aumentando, porém nas Ciências Exatas ainda é pequeno. Quanto a ser cientista, as mulheres representam quase metade dos registros do Conselho Nacional de Pesquisa (CNPq). Todavia, se for avaliar a quantidade delas por áreas, verifica-se que as Ciências Humanas e Biológicas concentram, aproximadamente, 74\% delas e as Ciências Exatas 26\% [Chassot, 2011a; Barreto, 2014; Bolzani, 2017; Cunha et al, 2014]. IAB (Interactive Advertising Bureau) Brasil [IAB 2015] e Information Systems Audit and Control Association [ISACA 2016] pesquisaram setores de TIC e confirmam que a mão de obra feminina nessa área também não passa de $25 \%$ do total.

Chassot (2011b) explica que os estigmas em relação à inteligência das mulheres foram constituídos num processo histórico-cultural que mantém interesses limitantes para as mulheres, fortemente forjados sobre bases religiosas, o que colaborou para sua manutenção histórica. Por detrás desses interesses, Chassot (2011b) acrescenta que os interesses capitalistas de não ter trabalhadoras que tivessem que parar devido à gestação e à lactação, por exemplo, podem ter estimulado a criação e difusão dos estigmas. Outras pesquisas corroboram que as razões mais contundentes para tais estigmas são de fontes sociohistóricas e culturais [Barreto 2014; Bolzani 2017; Cunha et al 2014].

Pesquisas mais recentes, como a de Aires et al (2018) e de Macedo et al (2018), mostram o quanto o machismo e a crença de que as mulheres são incapazes de lidar com tecnologia e ciências exatas ainda influenciam a não escolha pelos cursos dessas áreas. Ademais, atestam que aquelas que as escolhem ainda têm que lidar com diversos tipos de discriminação, humilhação e deslegitimação do seu trabalho simplesmente por serem mulheres [Macedo et al 2018; Maquiné 2017; Santos, Canever and Frotta 2011].

Todavia, pesquisas da área da psicologia social evidenciam que “[...] o desenvolvimento cultural se sobrepõe aos processos de crescimento, amadurecimento e desenvolvimento orgânico da criança, formando com ele um todo." [Vygotsky 1931, p. 21; Vygotsky and Luria 2007]. Isto quer dizer que a qualidade da educação, da inserção e participação cultural é que faz diferença no desenvolvimento geral do ser humano, independentemente, do sexo biológico.

Assim, são viáveis ações que combatam a manutenção dos pensamentos preconceituosos em relação às mulheres, de maneira geral e em relação à sua inteligência e capacidade, e ações que as estimulem a buscar também profissões na área das Ciências Exatas. Afinal, não se trata de condição biológica, mas de estigmas criados e consolidados historicamente.

\section{Ações de Extensão: Múltiplas Aprendizagens e Responsabilidade Social}

Ações de extensão têm como prerrogativa manter a relação com a comunidade externa por meio de cursos de formação mais curta do que aqueles de níveis regulares como Técnico, Superior e Pós-graduações em geral. Por meio da Extensão, pode-se oferecer cursos mais curtos independentes da formação prévia da pessoa. Sua dependência é mais em relação à demanda regional e a parcerias com comunidades locais [Brasil 2018]. Por meio de ações de extensão é possível fazer links entre os eixos de ensino e pesquisa, o que enriquece a formação dos alunos universitários de qualquer área, intensifica as relações da instituição superior com a comunidade local e colabora com o desenvolvimento científico teórico e aplicado.

Quanto à instituição educacional ofertante, trata-se de cumprir com mais uma de 
suas responsabilidades sociais. Costa et al (2007) fala dessa importância em oferecer mais cursos gratuitos para comunidade e, ao mesmo tempo, envolver os alunos e a instituição mais de perto com os problemas sociais locais. É importante o protagonismo dos alunos dos cursos regulares de modo que possam ter aprendizagens de formação humana ligada às questões sociais, de habilidades comportamentais e emocionais, além da oportunidade de aplicarem os conhecimentos técnico-científicos aprendidos no curso em que estão matriculados. Todas essas aprendizagens são demandadas, posteriormente, no exercício da cidadania e da profissão.

Nessa perspectiva, as ações de extensão contribuem, por um lado, para a formação integral dos alunos dos cursos regulares e, pelo lado institucional, colaboram com mais uma ação de responsabilidade social mais situada à sua localidade, além dos ganhos para a comunidade externa.

De acordo com essa visão, a ação de extensão Mulheres na Informática ocorreu a partir da relação dialógica entre o IFG e a prefeitura de Inhumas. Por meio da Secretaria de Promoção Social, do Centro de Referência da Assistência Social (CRAS), foram identificadas mulheres em comprovada situação de vulnerabilidade social por meio do Cadastro Único, necessitando de formação profissional para buscar reinserção no mercado de trabalho. A seguir, é descrita essa ação.

\subsection{Descrição da Ação de Extensão}

A ação em questão teve como título completo Mulheres na Informática: Da Informática Básica à Criação de Sites. A partir da delimitação da Informática como eixo principal da formação, o curso foi pensado dentro da concepção de articulação entre formação técnica e humana, visando à formação integral das estudantes. Assim, o curso foi organizado em 160 horas, distribuídas em dez meses de aulas presenciais nos laboratórios da instituição ofertante, com conteúdos de informática básica criativa, empreendedorismo, criação de sites e empoderamento feminino, conforme Quadro 1:

Quadro 1: Currículo da ação de extensão Mulheres na Informática

\begin{tabular}{|c|c|}
\hline Módulo & Ementa \\
\hline $\begin{array}{l}\text { Informática Básica } \\
\text { Criativa } \\
58 \text { horas }\end{array}$ & $\begin{array}{l}\text { Funções básicas do sistema operacional (ligar/desligar, manipulação de } \\
\text { pastas, configuração de vídeo, uso de pendrive, etc); Pacote LibreOffice } \\
\text { (Edição de texto, de slides e planilha); Básico de internet. }\end{array}$ \\
\hline $\begin{array}{l}\text { Empreendedorismo e } \\
\text { Inovação } \\
20 \text { horas }\end{array}$ & $\begin{array}{l}\text { Conceitos gerais de Empreendedorismo e Inovação. Modelagem de } \\
\text { Negócio. Modelo Canvas. } \\
\text { Motivação e Empoderamento de mulheres no mundo dos negócios e } \\
\text { inovação. }\end{array}$ \\
\hline $\begin{array}{l}\text { Gênero e } \\
\text { desenvolvimento } \\
\text { intelectual } \\
6 \text { horas }\end{array}$ & $\begin{array}{c}\text { Conceito de gênero. Desenvolvimento histórico-cultural humano. } \\
\text { Desigualdades de gênero. }\end{array}$ \\
\hline $\begin{array}{l}\text { HTML e CSS } \\
58 \text { horas }\end{array}$ & $\begin{array}{l}\text { Conceitos gerais de HTML. Abordagem dos elementos HTML e seus } \\
\text { atributos. CSS. Projeto básico de site completo. Ferramentas de } \\
\text { construção rápida de site e posts digitais. }\end{array}$ \\
\hline
\end{tabular}




\begin{tabular}{|c|c|}
\hline $\begin{array}{c}\text { Mulheres de Sucesso } \\
\text { Aí } \\
6 \text { horas }\end{array}$ & $\begin{array}{c}\text { Palestra com roda de conversa a respeito das mulheres no } \\
\text { empreendedorismo e inovação. } \\
\text { Entrevista com Mulheres de Sucesso. }\end{array}$ \\
\hline $\begin{array}{c}\text { Gênero e profissões } \\
\text { das Exatas } \\
6 \text { horas }\end{array}$ & $\begin{array}{l}\text { Motivação. Mulheres na Informática. Relato de experiência } \\
\text { profissional. }\end{array}$ \\
\hline 6 horas & Dinâmica: Mapa da Vida \\
\hline
\end{tabular}

A informática básica criativa compreendeu os conteúdos técnicos do pacote de escritório gratuito LibreOffice articulado com exercícios e projetos contextualizados, de maneira interdisciplinar e na criação de conteúdo digital pelas participantes, com temas que evidenciam relações com a sociedade: a) Descarte de lixo eletrônico; b) Crimes digitais (cyberbullying, preconceitos e atos de racismo e sexismo, compartilhamentos ilegais, etc.).

Os encontros do curso que trabalharam gênero e empoderamento feminino integraram ações como palestras e a dinâmica Mapa da Vida, visando conscientizar as mulheres participantes de que a inteligência delas pode ser desenvolvida ao longo da vida, conforme buscam esse tipo de ação de estudo e formação. O Mapa da Vida foi coordenado pela assistente social do câmpus, a fim de ajudar as participantes a repensarem sua situação, seu poder de decisão e sua reinserção profissional.

O módulo de Empreendedorismo teve por objetivo dialogar sobre as características comportamentais do/a empreendedor/a, as percepções de oportunidades e a determinação de transformar ideias em ação. As estudantes tiveram contato com conteúdos sobre planejamento e estratégias no mundo dos negócios, participaram de debates, estudos de caso e representação de papéis.

Durante os encontros do módulo de Empreendedorismo, a turma participou de atividades em grupo e as estudantes foram incentivadas e conduzidas a elaborarem um projeto. Foram apresentados diversos problemas sociais para que elas pudessem, por meio da técnica de Brainstorming, pensar numa solução. Após escolher uma temática, cada grupo elaborou um projeto no qual buscou fazer a conexão entre o material conceitual trabalhado e a realidade do tema escolhido. Para dar suporte ao planejamento e elaboração do projeto, foi utilizada a estrutura Canvas. Essa estrutura permite desenvolver um modelo de negócio empregando um esquema que guia a empresa na definição e implementação da estratégia por meio das estruturas, processos e sistemas organizacionais [Osterwalder and Pigneur 2011]. Felizmente, como resultado, tivemos estudantes entusiasmadas e envolvidas com a temática. Alguns projetos elaborados foram, Saúde Doce, Descarte Consciente, Delivery Fitness e Good Social. Na visão da professora, a experiência foi muito positiva, pois foi possível ver a aprendizagem dessas mulheres, bem como renovo de esperança de uma sociedade mais justa e igualitária.

Relacionado à criação de sites, utilizamos como material de apoio o site w3schools (https://www.w3schools.com/), que nos forneceu uma ampla variedade de conteúdo explicativo para que fossem elaboradas nossas aulas. Infelizmente, com a pandemia, tivemos que nos adaptar melhor para que nossas meninas não ficassem sem aula. Como a maioria delas não possuía computador em casa, passamos a utilizar o site 
Wordpress (https://br.wordpress.org/), que possui aplicativo para celular para que conseguíssemos finalizar o módulo via telefone móvel. De modo geral, elas se saíram bem, os conteúdos que foram apresentados a elas, tiveram como objetivo incentivá-las e mostrar que é possível fazer uma estrutura de um site de maneira fácil e rápida, visando despertar o interesse pela área profissional da informática e desmistificar os medos e dificuldades instaurados socialmente.

Mesmo após essa troca de plataforma, observamos que muitas delas se sentiam capazes em fazer seu próprio site. Houve ideias interessantes, tanto para seu próprio negócio, quanto para as empresas onde já trabalhavam. As maiores dificuldades que foram apresentadas por elas foram a falta de tempo para uma prática melhor do que foi mostrado dentro de sala de aula e também a falta de tempo para conseguir conciliar os estudos com trabalho e outros afazeres.

\subsection{Resultados e Discussão}

O curso começou com 28 alunas e ocorria todas as segundas, quartas e sextas à noite. Suas aulas tiveram início em outubro de 2019. A partir de março de 2020, ele foi adaptado para o modo online, mas permaneceram até o final apenas 5 alunas. Entretanto, 14 alunas concluíram em torno de 70 a $75 \%$ do curso, que foi o maior período presencial, e, então, elas receberam certificação intermediária.

O acompanhamento das participantes durante o curso mostrou que embora houvesse muitas delas com necessidade e desejo de reinserção no mercado, devido a diversos impedimentos pessoais elas não conseguiam uma constância na participação nas aulas noturnas, mesmo quando passou a ser a distância. Quando presencial, duas delas levavam as crianças juntas para faltar menos aulas. Outras faltavam alternando para poder alternar esse tipo de trabalho com quem estivesse em casa.

Assim, foi possível notar que a oferta de profissionalização para esse perfil de mulher precisa vir junto de apoio assistencial, de modo que elas possam ter condições de estudar. Isso quer dizer mesmo a distância, pois, mesmo nessa situação, aquelas com crianças pequenas não podiam dedicar-se a ficar duas horas estudando juntamente a uma situação familiar complexa.

Sobre o perfil das participantes, 55\% tinha entre 22 e 39 anos e tinham completado, no máximo, até o Ensino Médio. Aproximadamente, 30\% eram mães solteiras ou divorciadas. Todas as 28 inscritas afirmaram ter pouco ou nenhum conhecimento em Informática, embora 26 delas tenham afirmado que utilizam a Internet todos os dias via celular.

Algumas dificuldades enfrentadas, pela equipe proponente, foram: a) Laboratório de informática sucateado; b) Heterogeneidade da turma; c) Dificuldade de aprendizagem; d) Baixa autoestima; e) Irregularidade nas aulas.

Quanto à qualidade dos laboratórios, sugere-se para as próximas edições do curso ter um módulo sobre montagem e manutenção de computadores, pois, frequentemente, as aulas eram atrasadas ou interrompidas devido a problemas técnicos desse tipo que poderiam ter sido explorados. Esse problema reforça, também, a necessidade de financiamento para bens permanentes como os computadores.

Sobre a heterogeneidade da turma, talvez ao melhorar a divulgação, seja possível montar uma turma mais homogênea, ao menos, em termos de idade, ou, então, pensar 
em mais de uma turma, após as matrículas, para separar grupos menores.

Quanto às dificuldades de aprendizagem, notou-se maior dificuldade nos conteúdos de informática do que de empreendedorismo. Para contornar esse problema, os conteúdos eram problematizados apoiando-se em situações reais do dia a dia, para que visualizassem como aquilo poderia ajudá-las a se desenvolver ou a desenvolver um trabalho, por exemplo, na área de organização dos clientes de manicure e pedicure, organização de congelados, etc. Observamos que, após umas três ou quatro semanas de aulas, aproximadamente, algumas das participantes começaram a participar de outros eventos no câmpus e isso aumentou a motivação e a aproximação entre elas ao conversarem, aumentando também o interesse pelas aulas e em ajudar umas às outras.

A baixa autoestima e timidez foram, parcialmente, superadas conforme essa aproximação entre o grupo e com as professoras e bolsistas. Mesmo assim, algumas desistentes relataram não ter motivo específico, mas apenas consideraram não ter se integrado bem. As atividades da assistência social, algumas motivacionais ligadas ao empreendedorismo e as discussões sobre gênero também colaboraram para ajudá-las a enfrentar alguns sentimentos depreciativos. Algumas alunas afirmaram que o sonho delas era conseguir terminar e poder colocar no currículo aquele curso feito no IFG.

Sobre a irregular participação de algumas das alunas, o motivo mais relatado foi ter que cuidar de problemas familiares, como por exemplo, ter que ficar com os filhos ou com outro parente doente sob a responsabilidade delas por não ter outra pessoa que pudesse cuidar.

De modo geral, a participação das mulheres inscritas estava indo bem, porém, com o distanciamento social recomendado, as aulas foram temporariamente suspensas em março de 2020 e orientadas a voltar em abril de 2020. Nessa data, quando nos organizamos para voltar, apenas 6 alunas retornaram e as atividades e conteúdos foram adaptados para serem desenvolvidos por de celular smartphone, já que esse era o equipamento de posse da maioria das participantes.

Quanto às estudantes bolsistas, elas protagonizaram durante todo o curso, incluindo a preparação da divulgação que antecedeu as inscrições, depois o planejamento das aulas, a execução das aulas e o contínuo acompanhamento e comunicação com a turma. Isso proporcionou significativos ganhos para a formação delas, tanto em oportunidade para praticar conhecimentos técnicos, já que elas eram estudantes do Bacharelado em Sistemas de Informação, quanto para desenvolver outras habilidades como docência, planejamento do trabalho, produção de conteúdo digital, comportamento profissional e o conhecimento de problemas sociais da região.

\section{Considerações Finais}

O projeto em questão teve como objetivo geral oferecer formação em informática básica, noções de empreendedorismo, empoderamento feminino e iniciação ao desenvolvimento de sites a mulheres em situação de vulnerabilidade social do município de Inhumas. Para aquelas que concluíram as 160 horas do curso, tais objetivos foram alcançados, ou seja, foi oferecida e adquirida uma formação integrada entre conhecimentos técnicos, de informática e gestão, e conhecimentos de formação geral que contribuíram para a formação dessas mulheres. Do ponto de vista quantitativo, este projeto não atendeu as expectativas, pois, logo de início, quando foram ofertadas 50 vagas, foram preenchidas somente $32 \mathrm{e}$, ao final, concluíram todo o curso apenas 5 
alunas.

Ao longo da Ação, foi possível perceber diversos avanços em relação à aprendizagem das alunas, como, por exemplo, em situações básicas, tais como, ligar e desligar o computador, utilizar teclado e mouse, passar arquivos para pendrive, etc., elas não só aprenderam como perderam o medo do equipamento, o medo de tentar. Também tivemos depoimentos verbais das estudantes em que nos foi dito que o curso estava ajudando-as muito, tanto no trabalho, quanto no dia a dia, e que o aprendizado que estavam tendo estava facilitando suas vidas.

Além disso, ao final de cada módulo, elas apresentavam os projetos que vinham desenvolvendo como os sites e o plano de negócios e durante essas apresentações houve relatos de que gostaram muito dessas duas atividades e do Mapa da Vida. Relataram, inclusive, que perceberam que conseguem fazer as coisas sozinhas, que podem sonhar com um negócio próprio, que esse curso despertou vontade de voltar a estudar e concluir os estudos e buscar novas oportunidades. Elas, frequentemente, comentavam novos planos, alguns diferentes da área do curso. A maioria das participantes afirmou que o curso contribuiu para a vida profissional e pessoal delas. Assim, foi possível observar que, além dos conteúdos aprendidos, o conjunto integrado das ações do curso também despertou bons sentimentos e reflexões que podem ajudá-las a retomar outra linha de trabalho em suas vidas.

Quanto às relações com a prefeitura do município do câmpus Inhumas do IFG, o projeto também colaborou para abrir espaços para outras parcerias e projetos futuros.

Embora tenhamos destacado, desde o início, que há, atualmente, uma necessidade econômica que motiva as ações de incentivo às mulheres a buscarem profissões nas Ciências Exatas, em geral, quando se associa, também, a necessidade da superação das desigualdades de gênero, contribui-se para uma sociedade culturalmente mais desenvolvida e igualitária.

Os dados analisados quanto à situação doméstica de cada inscrita na ação aqui relatada comprovam que a situação delas de vulnerabilidade não pode ser superada apenas com a oferta de cursos profissionalizantes gratuitos, pois, muitas possuem vontade e interesse, mas, simplesmente, não conseguem contornar dificuldades familiares e financeiras de modo a permanecer e concluir um curso. É imprescindível, de maneira paralela, oferecer apoio assistencial diverso. Assim, ações de empoderamento e capacitação de mulheres representam apenas uma parte de um complexo conjunto de ações que precisam, de fato, ser promovidas para aquelas em situação vulnerável, se o desejo é sua transformação social. É importante trazer à lembrança que esse tipo de investimento, a médio e longo e prazo, impacta no desenvolvimento geral do país. Logo, é algo que vai muito além das lutas do grupo específico, seja a motivação inicial pela luta por uma sociedade menos machista ou pelo seu interesse econômico.

\section{Referências Bibliográficas}

Aires, J., Mattos, G., Oliveira, C., Britto, A., Aragão, A. F., Alves, S., Coelho, T. and Moreira, G. (2018) Barreiras que Impedem a Opção das Meninas pelas Ciências Exatas e Computação: Percepção de Alunas do Ensino Médio. In Anais do XXXVIII Congresso da Sociedade Brasileira de Computação (SBC) / $12^{\circ}$ WIT - Women in Information Technology. UFRN - Natal, de 22 a 26 de julho de 2018. Disponível em: 
$<$ http://natal.uern.br/eventos/csbc2018/?page_id=370>

Barreto, A. (2014) A mulher no ensino superior: distribuição e representatividade. Cadernos do GEA, n. 6, jul./dez. Disponível em: $<$ http://flacso.org.br/files/2016/04/caderno_gea_n6_digitalfinal.pdf $>$ Acesso em 27 set. 2019.

Bolzani, V. da S. (2017) Mulheres na ciência: por que ainda somos tão poucas?. Cienc. Cult., São Paulo, v. 69, n. 4, p. 56-59, Oct. Disponível em: <http://dx.doi.org/10.21800/2317-66602017000400017. >. Acesso em 27 Set. 2018.

Brasil. (2018) Ministério da Educação. Conselho Nacional de Educação/Câmara de Educação Superior - CNE/CES. "Diretrizes para a Extensão na Educação Superior Brasileira". Resolução $n^{\circ} 7$ de 18 de dezembro de 2018.

CGI.br. (2019) Comitê Gestor da Internet no Brasil. "Pesquisa sobre o uso das tecnologias de informação e comunicação nos domicílios brasileiros: TIC domicílios 2018”. São Paulo: Comitê Gestor da Internet no Brasil.

Chassot, A. (2011a) “A ciência é masculina?” 5. ed. São Leopoldo: Editora Unisinos.

Chassot, A. (2011b) “A ciência é masculina? É, sim senhora!...” Programa de PósGraduação Unisinos. Disponível em: $<$ http://www.cimm.ucr.ac.cr/ciaem/memorias/xii_ciaem/124_ciencia_masculina.pdf $>$ Acesso em: 28 nov. 2020.

Costa, R. L. (2020) As recomendações de uso de tecnologias digitais da informação e comunicação para a educação básica e a realidade escolar brasileira. Revista Anápolis Digital, v. 11, n. 2. Acesso em mar. 2021. Disponível em: $<$ https://portaleducacao.anapolis.go.gov.br/revistaanapolisdigital/?p=653>

Costa, R. L., Thereza Júnior, A. H., Gomide, R. S., Gomide, R. do V. S. and Damasceno, E. F. (2007) "Informática Básica nas Escolas Públicas Buscando a Inclusão Digital dos Estudantes da Oitava Série do Ensino Fundamental em Diante e da Comunidade em Geral". In Anais do Workshop de Informática na Escola 2007. Disponível em $<$ https://www.br-ie.org/pub/index.php/wie/issue/view/32> Acesso em 22 mar. 2021.

Costa, R. L. da, Thereza Júnior, A. H., Guinati, D. de S. and Sousa, S. de C. (2019). Ações de extensão para integrar mulheres em vulnerabilidade social na área de tecnologias da informação e comunicação. Revista UFG, 19. Disponível em: <https:// doi.org/10.5216/revufg.v19.60623> Acesso em 20 mar. 2021.

Cunha, M. B. da, Peres, O. M. R., Giordan, M.; Bertoldo, R. R., Marques, G. de Q. and Duncke, A. C. (2014) As mulheres na ciência: o interesse das estudantes brasileiras pela carreira científica. Educ. Quím., 25 (4), 407- 417.

IAB. (2015) Interactive Advertising Bureau Brasil. "A liderança alfa e as empresas de TI no universo feminino”. Disponível em: <http://iabbrasil.com.br/a-lideranca-alfa-eas-empresas-de-ti-no-universo-feminino/> . Acesso em: 24 maio 2021.

IBGE. (2017) Instituto Brasileiro de Geografia e Estatística. "Estatísticas do cadastro central de empresas”. Rio de Janeiro.

IBGE. (2018) Instituto Brasileiro de Geografia e Estatística. "Pesquisa nacional por amostra de domicílios (PNAD) contínua”. Rio de Janeiro. 
IPEA. (2018) Instituto de Pesquisa Econômica Aplicada. "Atlas da Violência no Brasil”. Fórum Brasileiro de Segurança no Brasil.

ISACA. (2016) Information Systems Audit and Control Association. "The future tech workforce: breaking gender barriers". Disponível em: $<\mathrm{http}$ //www.isaca.org/info/2017-women-in-technology-survey/index.html>. Acesso em: 25 maio 2021.

Macedo, M. M. G., Mattos, A. B., Vasconcelos, M., Martinazzo, A. and Lopes, R. (2018) Identificando Influências na Escolha de uma Graduação em Exatas: um Estudo Qualitativo e Comparativo de Gênero. In Anais do XXXVIII Congresso da Sociedade Brasileira de Computação (SBC) / $12^{\circ}$ WIT - Women in Information Technology. UFRN - Natal, de 22 a 26 de julho de 2018. Disponível em: $<$ http://natal.uern.br/eventos/csbc2018/?page_id=370>

Maquiné, C. C. (2017) "Contribuição das mulheres nas ciências exatas: Levantamento histórico". Trabalho de conclusão de curso. Universidade Federal de São João Del Rey, Minas Gerais. Departamento de Licenciatura em Matemática.

Osterwalder, A. and Pigneur, Y. (2011) "Business Model Generation: Inovação em Modelos de Negócios". Rio de Janeiro: Alta Books.

Rocha, B. N., Cury, R. L. C., Marguti, B. O. and Costa, M. A. (2017) “A nova plataforma da vulnerabilidade social: Primeiros resultados do índice de vulnerabilidade social para a série histórica da Pnad (2011-2015) e desagregações por sexto, cor e situação de domicílio”. Atlas da Vulnerabilidade Social.

Santos, A. C., Canever, C. F. and Frotta, P. R. de O. (2011) A influência do gênero na escolha profissional de pré-vestibulandos: estudo de caso na cidade de Criciúma/SC. Revista Travessias, V. 5, n. 2.

Softex. (2013a) "Cadernos Temáticos do Observatório: Mercado de Trabalho e Formação de Obra em TI - Softex". Arquivo eletrônico disponível em: $<$ https://www.softex.br/inteligencia/\#cadernostematicos.>

Softex. (2013b) "Cadernos Temáticos do Observatório: Economia da Informação e Internet - Softex". Disponível em: $<$ https://www.softex.br/inteligencia/\#cadernostematicos.>

Vygotsky, L. S. (1931) “Historia del Desarrollo de las Funciones Psíquicas Superiores ”. Obras Escogidas Tomo III. Comisión editorial para la edición en lengua rusa. Academia de Ciencias Pedagógicas de la URSS.

Vygotsky. L. and Luria, A. (2007) “El instrumento y el signo en el desarrollo del niño”. Edición a cargo de Pablo del Río y Amelia Álvarez. Fundación Infancia y Aprendizaje.

\section{Agradecimentos}

Pró-reitoria de extensão do IFG pelo apoio institucional e fomento de bolsas a estudantes de cursos superior. 